Article

\title{
Emerging Consumer Healthy Lifestyles in Lithuania
}

\author{
Agnè Gadeikienè ${ }^{1, *}$, Laura Šalčiuvienè ${ }^{2}$, Jūratė Banyte் ${ }^{1} \mathbb{D}$, Aistè Dovalienè ${ }^{1}$, Mindaugas Kavaliauskas ${ }^{3}$ \\ and Žaneta Piligrimiené ${ }^{1}$ (D)
}

1 School of Economics and Business, Kaunas University of Technology, Gedimino Str. 50, LT-44239 Kaunas, Lithuania; jurate.banyte@ktu.lt (J.B.); aiste.dovaliene@ktu.lt (A.D.); zaneta.piligrimiene@ktu.lt (Ž.P.)

2 Department of Marketing, Lancaster University Management School, Lancaster LA1 4YX, UK; 1.salciuviene@lancaster.ac.uk

3 Department of Applied Mathematics, Faculty of Mathematics and Natural Sciences, Kaunas University of Technology, Studentu Str. 50, LT-51368 Kaunas, Lithuania; m.kavaliauskas@ktu.lt

* Correspondence: agne.gadeikiene@ktu.lt

check for updates

Citation: Gadeikienè, A.;

Šalčiuvienė, L.; Banytė, J.; Dovalienė, A.; Kavaliauskas, M.; Piligrimienè, Ž. Emerging Consumer Healthy Lifestyles in Lithuania. Sustainability 2021, 13, 10056. https://doi.org/ $10.3390 /$ su131810056

Academic Editor: Marc Lim

Received: 7 July 2021

Accepted: 2 September 2021

Published: 8 September 2021

Publisher's Note: MDPI stays neutral with regard to jurisdictional claims in published maps and institutional affiliations.

Copyright: (C) 2021 by the authors. Licensee MDPI, Basel, Switzerland. This article is an open access article distributed under the terms and conditions of the Creative Commons Attribution (CC BY) license (https:// creativecommons.org/licenses/by/ $4.0 /)$.

\begin{abstract}
Consumer lifestyle is considered one of the important predictors of sustainable consumption behavior at the individual, community and societal levels. In this paper, the healthy lifestyle of consumers is analyzed and defined as the lifestyle that explains how people live in terms of health. This study focuses on consumers' healthy lifestyle clusters and offers an updated healthy lifestyle measurement tool that can be used to segment consumers into specific segments according to six healthy lifestyle domains: physical, mental, emotional, social, spiritual and intellectual health. An online survey with 645 respondents of different socio-demographic profiles was conducted in Lithuania. Based on data collected through questionnaires, specific segments were identified using self-organizing maps and cluster analysis methods. The findings suggest that four different segments could represent consumers concerning their healthy lifestyles. The results will be of use to companies initiating marketing campaigns to target different consumer groups with their brands and offering healthy lifestyle-related products and services to consumers in Lithuania. The findings are also valuable for public policymakers and opinion leaders who foster healthy lifestyles and seek to form a public opinion regarding sustainable consumption.
\end{abstract}

Keywords: healthy lifestyle; consumer segments; Lithuanian consumers; self-organizing maps (SOM); cluster analysis; sustainable consumption

\section{Introduction}

Wellbeing is thought to be one of the core drivers of consumer behavior that will affect global markets over the next 10 years [1]. The global consumer trends emphasize the acceleration of changed consumer lifestyle conditions due to the pandemic in 2021 [2], referring to shaken and stirred consumers who strive for a more balanced life. These global circumstances enforced the development of new consumption models, especially relevant to the virtual environment and emphasizing sustainable consumption (e.g., secondary usage of products, sharing of underused assets among consumers). It is forecasted, that these newly formed consumer habits will remain and strengthen sustainability trends in consumption [3]. In this context, special attention is given to mental wellbeing, which is considered one of the main good health indicators more often [4]. The pandemic has had a significant impact on consumer beliefs, norms and values related to their wellbeing and health. This confirms the timeliness of healthy lifestyle research.

Lifestyle can be defined as a system that relates situation-specific product perception, knowledge, habits, general beliefs and personal values [5]. Jensen [6] emphasizes that a lifestyle definition highly depends on the research field, and it includes assumptions on how a person lives or would like to live, what a person consumes and how he/she approaches health-related aspects that correspond to purchasing decisions and consumption practices. 
Thus, a lifestyle is a long-term determinant of consumer behavior. The concept of a lifestyle can be studied at different levels: global, national (or cultural), reference group (or subcultural) and individual [6]. In this paper, we analyze the lifestyle at the individual level, that is, we understand the lifestyle as a system reflecting the person's self-identity, personal values, perception, motivation, habits and beliefs [6-8].

Lubowiecki-Vikuk et al. [8] note that a lifestyle or separate elements of it are often investigated in studies related to sustainability because they are tightly associated with the UN's objectives of sustainable development. In this regard, research that analyzes sustainable life, consumption characteristics and their antecedents becomes of high relevance [9]. Recent research on consumer lifestyles emphasizes them as being one of the key antecedents influencing sustainable consumption behavior at the individual, community or societal level [8-11]. In sustainable consumption research, authors choose to study different constructs of lifestyles. For instance, Wardle and Steptoe [12], Kim and Kang [13] study healthy lifestyles, Evans and Abrahamse [14]—sustainable lifestyles, Lorenzen [15]—ecological lifestyles, Thogersen [16]—food-related lifestyles, Picha and Navratil [9]-lifestyles of health and sustainability (LOHAS). Our study focuses on identifying lifestyles of health through an innovative method of self-organizing mapping (SOM) for segmentation in the post-pandemic context.

Lim [17] who offered a theoretical toolbox for future sustainable consumption research reasons the link between healthy lifestyles and sustainable consumption at a conceptual level. The authors of this article support the reasoning of the discussed relationship with one of the theoretical perspectives of consumer behavior identified by Lim [17] -responsible consumption. According to Lubowiecki-Vikuk et al. [8], responsible consumption is closely linked with the lifestyle of individuals. Responsible consumption includes social, environmental and ethical concerns and decisions. This confirms the role of a holistic healthy lifestyle construct as a determining factor in responsible consumption. In support of Lim's [18] call for more research on the holistic approach in sustainable marketing research through the examination of ethical and technological dimensions in addition to the economic, environmental and social dimensions, it can be stated that (1) sustainable consumption can be addressed as a consequence of sustainable marketing in relation to healthy lifestyles and (2) future research on healthy lifestyles' effect on sustainable consumption should integrate both technology and ethics factors.

The above-mentioned aspects support the argument that the conceptualization of the consumer healthy lifestyle is ambiguous and requires considering recent environmental and market-related changes that impact the transformation of consumption patterns, consumer beliefs, perceptions and habits. Therefore, the aim of this paper is to explain the phenomenon of consumer healthy lifestyles by distinguishing emerging healthy lifestyles among consumers of Lithuania.

The paper offers two contributions. First, it contributes to the sustainability-focused consumer behavior research stream and extends our understanding of the holistic consumer healthy lifestyle approach. Until now, the majority of consumer healthy lifestyle studies focused on physical activities and/or nutrition (e.g., [19,20]). There is a lack of research integrating mental and spiritual wellbeing, stress management and other aspects of general consumer wellbeing into the holistic conceptualization of the healthy lifestyle. The second contribution concerns the development of a measurement scale and identification of healthy lifestyle segments in the case of Lithuanian consumers using a novel SOM approach in the sustainability and consumer research field. We believe that these contributions are important from both theoretical and practical perspectives, especially due to the long-lasting context of the pandemic, which influences changing consumption patterns. The findings of this study also contribute to the new stream of research analyzing post-pandemic behavioral changes among consumers. 


\section{Literature Review}

\subsection{Healthy Lifestyle Domains}

In this paper, we focus on healthy lifestyle domains discussed through LOHAS healtharea-related research, which highlights healthy lifestyle dimensions. Those are as follows: physical health, mental health, emotional health, social health, intellectual health and spiritual health. We also consider those dimensions from both content and breadth of research conducted for each dimension. We will briefly present each of those below.

Physical health is linked to an individual's effort to remain healthy in order to be able to carry on with everyday tasks [21]. Wardle and Steptoe [12] and Yap and Othman [20] promoted health activities to prevent illnesses: to maintain good physical health, an individual has to perform physical activities and exercise to keep up the strength of their muscles. Wardle and Steptoe [12] and Kim and Kang [13] suggest that a healthy diet is important as nutrients are essential elements to keep the body going and a key to maintain regular exercise. Eating healthily and exercising regularly prevents, or reduces, the probability of drug, alcohol and cigarette consumption [22,23]. Such a healthy lifestyle also reduces the need for any medical service, or, at least, it increases the number of healthily lived years [21]. Physical health is also related to health prevention efforts to regularly visit healthcare professionals [24] and the use of novel technologies to monitor health indicators [25].

Mental health is related to an individual's effort to feel mentally healthy by spending some time on relaxing activities, rest and practicing special exercises to release stress and anxiety. Taking some time to relax every day and meditate along with using specific methods to control stress and attempting to reduce anxiety $[13,24,26]$ contribute positively to one's mental health [26]. A study by Maenhout et al. [23] contributes to the mental health domain of healthy lifestyles and shows that physical and mental health are closely linked. They identify such activities as sufficient sleep, physical activity, breakfast on a daily basis, low levels of tobacco and alcohol use and indicate their strong links with good mental health. On the contrary, variations in both sleep and diet might negatively influence the healthy lifestyle of an individual [27].

We agree with Choi [21] that emotional health refers to an individual's ability to maintain a positive attitude toward life and toward self, and people around them. Previous research suggests that emotions impact healthy lifestyles and the motivation of individuals to live healthily and use self-determination theory to explain this phenomenon [28]. Also, enjoyment and satisfaction with life and their surroundings contribute positively to the maintenance of emotional health $[13,21,26]$. The general perception of health affects mental and social wellbeing, reduces stress, anxiety and depression, while healthy activities contribute to healthy lifestyles [22]. Nedly and Ramirez [29] state that wellbeing and happiness can be optimized with healthy coping strategies that contribute to emotional health. Trigueros et al. [28] also suggest that emotional wellbeing is becoming a health trend among millennials.

Social health refers to the ability to maintain healthy and active social relationships with other people $[21,24,30]$. Both communication and affection define social health [31] in 21]. Furthermore, it refers to receiving and providing help to other people in the social network [21,26], attempting to be a valuable member of society [30] and actively engaging in social activities and meaningful, and enjoyable socialization [15,22].

Intellectual health refers to an ability to advance oneself through pursuing selfdevelopment through, for example, reading and finding a purpose of utilizing the ideas found in media or books [32]. It is also related to abilities and curiosity to learn new things, to process and evaluate information, to choose among alternatives [10], to share knowledge and know-how with others [24].

Spiritual health refers to "the development of inner resources to maximize human potential" [21] (p. 18) and can be better researched through inner harmony, peace, or feel of connectedness to other like-minded people and/or Greater Force [33]. Spiritual health depends on the individual's worldview and understanding of the purpose of life [34]. 
The above-described domains reflect the holistic approach to healthy lifestyles when they are analyzed as one system of consumer personal values, attitudes, beliefs and perceptions. In this paper, the holistic approach is used for the consumer segmentation using healthy lifestyles of consumers.

\subsection{Consumers Living Healthy Lifestyles}

Previous literature on consumers who adopt healthy lifestyles can be divided into two groups. The first group of studies analyses consumers following healthy lifestyles with a focus on physical health as the majority of consumers are interested in personal wellbeing and their personal health [21]. Those studies mainly focus on four healthy lifestyle domains: physical activity, nutrition, surroundings and home and (preventive) medical care.

For instance, Park [35] studied upcycling fashion goods, consumer trust and purchase intentions of consumers who follow healthy lifestyles. Hustvedt, Peterson and Chen [36] examined consumer perceptions of organic fiber products and segmented consumers accordingly based on demographics and psychographics. Kim and Chung [37] contributed to studying US consumer preferences for organic personal care products and found that appearance consciousness and environmental consciousness influence consumer attitudes and buying intentions in the organic personal care market. Such consumers, who can be segmented into healthy lifestyles segments, usually are interested in buying products contributing to their physical fitness, enhancing their health and their home surroundings [21].

Divine and Lepisto [19] approach healthy lifestyles as corresponding to consumers' physical activity and nutrition habits (healthy or not healthy). Yap and Othman [20] group consumers into two healthy lifestyle groups according to their level of physical activity, arguing that there are significant differences between "low active" and "high active" exercisers. Essoussi and Zahaf [38] analyzed a segment of consumers in the Canadian food market and uncovered consumer motivation and organic food recognition patterns within the mainstream and niche community market of organic food consumers. Kim, Lee, Kim and Kim [39] suggested that there is a difference between the senior market segment and the non-senior market segment, and the differences manifest themselves in healthy food choices, trust and emotional loyalty through the healthy lifestyles perspective. Evans and Abrahamse's [14] contribution suggested that healthy lifestyles give individuals self-identity and self-actualization. To live such lifestyles, individuals would treat them as a "life project" and sometimes even tend to follow extreme health-related diets, purchase organic food and follow healthy cooking procedures and recipes [14].

In the healthy lifestyles segments, marketers observe that consumers use daily supplements and buy environmentally and society-friendly goods [21]. Uzzan, Nechrebeki and Labuza [40] discovered that milk enriched with different ingredients could be used as a medicine that might promote the length of healthy lives of those over 55 and contribute to their healthy lifestyles. Chen [41] found that for consumers to stay healthy, they need to use functional foods which reduce the risk of illnesses. He also suggested that both health consciousness and healthy lifestyles of individuals contribute to the willingness to consume functional foods as they contribute to lower levels of cholesterol and blood pressure and improve other bodily functions. He identified two groups of consumers, namely, the "Healthy life attentive" and "Healthy life inattentive" groups. The first group had more desire and willingness to follow a healthy lifestyle, while the second group had lower health consciousness and felt less need for functional foods. Individuals who care about their health, follow physical therapists closely as they represent health and offer relevant physical activities to their patients [42,43]. Besides, they avoid consumption of unhealthy substances such as alcohol or sugar and they do not smoke [22].

Consumers attempt to value alternative medical care to feel better as they care about their physical health [21]. Tindle, Davis, Phillips and Eisenberg [44] studied trends of complementary and alternative medicine in the US that is used by one in three consumers to maintain their healthy lifestyles and found that those consumers value conventional care as much as alternative medicine but seek the latter for their beliefs that it will positively 
influence their physical and mental health. Lee, Chang and Du [45] found that people with healthier lifestyles are more engaged in preventive healthcare services and visit their physicians more frequently with the aim to examine their health conditions. Küçük [46] suggested that individuals who had chronic illnesses had a better tendency to consume nutritional foods and the spiritual development among such individuals was comparably higher. However, there is a need to identify the beliefs of individuals, which could contribute to the formation of healthy lifestyle behavior [47].

Emerich [48] suggested that consumers who follow healthy lifestyles cared about their health and did so when health products and services were presented as a combination of physical, mental and spiritual elements [21]. Thus, the second group of studies refers to other healthy lifestyle domains that complement physical health and emphasize the holistic approach to healthy lifestyles. In this regard, consumers are viewed as interested and seek their full potential through aiming to better understand their deeper self [21]. Authors emphasize the holistic approach to a person's wellbeing, including various domains of healthy living [30].

Lara et al. [30] developed a holistic characterization of the "healthy aging phenotype", comprising five domains: physical activity; physiological and metabolic health; cognitive function; psychological wellbeing and social wellbeing. Hanawi et al. [22] emphasized psychological aspects which could be increased when adopting a healthy lifestyle in daily life. Choi and Feinberg [26] analyzed individual motivation not only for physical, but also emotional, mental and spiritual areas of a healthy life. The balance of body, spirit and mind contributes to personal development, helps to heal and feel good [21], as well as contributes to the wellness and health of people [49]. Vice versa, health-related practices are transformed in harmony with consumers' environment, their community and society as a whole [8].

\subsection{Healthy Lifestyle-Based Consumer Segmentation}

Various studies have segmented consumers using lifestyles (for example, $[9,19,20,26,50]$. Originally, the focus of such consumer segments was on health, fitness, environment, personal development, sustainable living and social justice $[8,48]$ and resulted in five subsegments [51,52]. In this paper, we segment consumers using healthy lifestyle domains.

Natural Marketing Institute [53] has published a report about consumers interested in healthy lifestyles, their beliefs and purchase decisions. The research suggests five consumer segments with the lifestyle of health and sustainability (LOHAS) segment being the most responsible and consuming the higher proportion of green products (i.e., products that do not contain pesticides, preservatives or artificial colors) in the market. The Institute also provides a very detailed profile of such consumers [53]. Other segments are naturalities, drifters, conventionals, and unconcerned and each of them is presented in the order reflecting a decreasing level of orientation to health and sustainability in comparison to the LOHAS segment [53].

In the scientific literature, many have attempted to replicate this research and reveal the culture- or country-specific peculiarities of the LOHAS scale and/or segment the market based on specific characteristics. For example, Szakály et al. [54] distinguished five Hungarian consumer clusters of lifestyle of health and sustainability (young trend followers; ethical traditionalists; young environmentally conscious people; uninvolved elderly people; and disappointed pessimists). Picha and Navratil [9] implemented their research in the Czech Republic and identified three segments (interested in LOHAS; partially interested in LOHAS, and not interested in LOHAS). These authors confirmed that gender can and does differentiate consumer segments. Also, those segments can be characterized by specific buying behavior such as purchasing local products and socially responsible consumption. Ottman [51] differentiated among five segments of green consumers.

Generalizing, it can be stated that in previous studies, segmentation is mainly based on the beliefs and values of consumers and their attitudes toward their lifestyles. However, there is a disagreement in findings in the academic literature about whether demographics 
can be used as a consumer characteristic that defines a segment. For example, previous studies suggest that while gender and age have a specific differentiation power in such segments $[9,19]$, income level does not have any influence on the determination of specific segments [19].

\section{Research Framework}

\subsection{Method and Sample}

Seeking to identify healthy lifestyles common among Lithuanian consumers, we employed the quantitative approach and carried out an online survey for data collection. This method is suitable for the self-reported data collection that is necessary for the measurement of different consumer attitudes in different health domains researched in this study. The general research population refers to all adults in Lithuania (starting from 18 years old) as they are conscious consumers and follow their own consumption standards. To select our sample, we applied the non-probability voluntary sampling with some aspects of stratified sampling procedures [55]. In this way, we ensured that our sample proportionally corresponds to all age and gender groups of the population. To collect our data, we used the SurveyMonkey platform and a target audience panel. Later, we collected additional responses from those age and gender groups which did not have a sufficient amount of fully completed questionnaires.

\subsection{Measures}

The main part of the questionnaire was dedicated to measuring six domains of healthy lifestyles. We employed items from the LOHAS scale [21]. The LOHAS scale is traditionally used to measure both healthy and sustainable lifestyles. Considering the scope of this particular study, we excluded items measuring sustainable lifestyles. Also, we adapted the scale to the Lithuanian context. We included items that reflect new tendencies in the daily lives of consumers (e.g., q0002_0010 "I monitor my health metrics (like heart rate) every day using a smart watch, a bracelet, or other devices"). Some of the items were added due to the importance to the Lithuanian consumers (e.g., in the q0002_0003 "I limit the consumption of foods that contain fat, gluten or added sugar" we included gluten as Lithuanian consumers consider it as a substance consumption which should be controlled). Some items were excluded as no longer relevant to the Lithuanian context. The measurement scale consisted of 35 items, and it measured the healthy lifestyle construct:

- A 10-item scale was used to measure physical health. It is based on Choi [21], Taymoori [24], Kim and Kang [13], Choi and Feinberg [26], Sielicka-Różyńska, Jerzyk and Gluza [56], Isakadze and Martin [25].

- Mental health $[13,21,24,26]$ and spiritual health [21,26] were measured with sixitem scales.

- $\quad$ Five items were used to measure emotional health $[13,21,26]$.

- Four items were dedicated to each of the social health aspects [21,24] and another four items-to intellectual health [21,24].

A seven-point Likert type scale was applied for each item, ranging from 1 ("Totally disagree") to 7 ("Totally agree"). At the end of the questionnaire, respondents were asked to provide their socio-demographic information.

\section{Results}

\subsection{Respondents' Characteristics}

At the end of the data collection period, 751 responses were collected. However, after a brief inspection of the results, 106 of them were excluded as not valid for further analysis. Thus, 645 responses were considered as suitable for the data analysis. Table 1 presents the socio-demographic characteristics of the respondents. It can be seen that respondents represented Lithuanian consumers quite proportionally according to gender $(39.4 \%$ males and $60.6 \%$ females), age group (15.0\% below $29,29.1 \%$ aged $30-44,29.8 \%-45-60$ and $26.0 \%$ over 60 ) and average personal income per month (i.e., $25.1 \%$ is paid less than the 
average salary, $30.8 \%$ have their income of the average salary level, $12.0 \%$ get higher incomes than the average salary, and $11.5 \%$ did not specify). In addition, respondents represented all the districts of Lithuania. A majority of them were from the two largest districts of Vilnius and Kaunas (57.0\%), 21.3\% of respondents represented the other two large districts and other districts were represented by $21.7 \%$ of respondents.

Table 1. Socio-demographic characteristics of the respondents and Lithuanian population [57].

\begin{tabular}{|c|c|c|c|c|c|}
\hline \multirow{2}{*}{ Characteristic } & \multirow{2}{*}{ Values } & \multicolumn{2}{|c|}{ Respondents } & \multicolumn{2}{|c|}{ Lithuanian Population } \\
\hline & & Frequency & Percentage & Frequency & Percentage \\
\hline \multirow{2}{*}{ Gender } & Male & 254 & 39.4 & $1311 \mathrm{~K}$ & 46.9 \\
\hline & Female & 391 & 60.6 & $1485 \mathrm{~K}$ & 53.1 \\
\hline \multirow{4}{*}{ Age group } & $18-29$ & 97 & 15.0 & $409 \mathrm{~K}$ & 17.6 \\
\hline & $30-44$ & 188 & 29.2 & $538 \mathrm{~K}$ & 23.2 \\
\hline & $45-60$ & 192 & 29.8 & $651 \mathrm{~K}$ & 28.1 \\
\hline & $>60$ & 168 & 26.0 & $722 \mathrm{~K}$ & 31.1 \\
\hline \multirow{8}{*}{$\begin{array}{l}\text { Average personal } \\
\text { income per month }\end{array}$} & $<300$ Euros & 66 & 10.2 & - & - \\
\hline & 301-500 Euros & 96 & 14.9 & - & - \\
\hline & 501-800 Euros & 133 & 20.6 & - & - \\
\hline & 801-1000 Euros & 97 & 15.0 & - & - \\
\hline & 1001-1500 Euros & 102 & 15.8 & - & - \\
\hline & 1501-2000 Euros & 45 & 7.0 & - & - \\
\hline & $>2000$ Euros & 32 & 5.0 & - & - \\
\hline & Not specified & 74 & 11.5 & - & - \\
\hline \multirow{7}{*}{$\begin{array}{l}\text { Household } \\
\text { structure }\end{array}$} & I live alone & 130 & 20.2 & - & - \\
\hline & $\begin{array}{l}\text { I live with relatives (not as a } \\
\text { couple/not married) }\end{array}$ & 89 & 13.8 & - & - \\
\hline & $\begin{array}{l}\text { I live as a couple/marriage without } \\
\text { child(ren) }\end{array}$ & 162 & 25.1 & - & - \\
\hline & $\begin{array}{c}\text { I live as a couple/marriage with } \\
\text { small child(ren) }\end{array}$ & 145 & 22.5 & - & - \\
\hline & $\begin{array}{l}\text { I live as a couple/marriage whose } \\
\text { child(ren) has grown up and living } \\
\text { independently }\end{array}$ & 98 & 15.2 & - & - \\
\hline & $\begin{array}{l}\text { I am a single mother/father } \\
\text { supporting a child(ren) }\end{array}$ & 17 & 2.6 & - & - \\
\hline & Not specified & 4 & 0.6 & - & - \\
\hline \multirow{11}{*}{ District } & Alytus district & 26 & 4.0 & $132 \mathrm{~K}$ & 4.7 \\
\hline & Kaunas district & 195 & 30.2 & $567 \mathrm{~K}$ & 20.4 \\
\hline & Klaipeda district & 74 & 11.5 & $322 \mathrm{~K}$ & 11.5 \\
\hline & Marijampole district & 18 & 2.8 & $135 \mathrm{~K}$ & 4.8 \\
\hline & Panevezys district & 25 & 3.9 & $208 \mathrm{~K}$ & 7.4 \\
\hline & Siauliai district & 63 & 9.8 & $260 \mathrm{~K}$ & 9.3 \\
\hline & Taurage district & 23 & 3.6 & $90 \mathrm{~K}$ & 3.2 \\
\hline & Telsiai district & 24 & 3.7 & $129 \mathrm{~K}$ & 4.6 \\
\hline & Utena district & 24 & 3.7 & $123 \mathrm{~K}$ & 4.4 \\
\hline & Vilnius district & 173 & 26.8 & $830 \mathrm{~K}$ & 29.7 \\
\hline & Total & 645 & 100.0 & $2796 \mathrm{~K}$ & 100.0 \\
\hline
\end{tabular}

\subsection{Data Analysis}

\subsubsection{Construct Structure and Measurement Quality}

The first step in the data analysis is the determination of the construct validity and reliability evaluation. As we applied an adapted scale for the measurement of the healthy lifestyle domains, we started our analysis with the construct structure exploration. For this purpose, we employed an exploratory factor analysis (method: principal components; rotation: Varimax). Table 2 presents the results of factor analysis. As can be seen, eight 
factors were extracted that explain the latent construct of a healthy lifestyle. The total variance explained was equal to $65.6 \%$, which is of the sufficient level [58].

Table 2. The structure of the healthy lifestyle construct: results of factor analysis, construct validity and reliability measures.

\begin{tabular}{|c|c|c|c|c|c|}
\hline Item Code & Measurement Item & Factorial Weight & Cronbach's Alpha & CR & AVE \\
\hline \multicolumn{6}{|c|}{ Spiritual Health (SPIRIT) } \\
\hline q0007_0003 & I nurture my spirituality. & 0.872 & \multirow{6}{*}{0.876} & \multirow{6}{*}{0.906} & \multirow{6}{*}{0.619} \\
\hline q0007_0002 & I feel connected with some Force greater than myself. & 0.848 & & & \\
\hline q0007_0004 & $\begin{array}{l}\text { I spend some time every day in prayer, meditation, or } \\
\text { personal reflection. }\end{array}$ & 0.838 & & & \\
\hline q0007_0005 & I feel a spiritual connection with other people. & 0.808 & & & \\
\hline q0007_0006 & I share my joy, love and peace with others. & 0.705 & & & \\
\hline q0007_0001 & I know the meaning of life and I have my own goal for it. & 0.620 & & & \\
\hline \multicolumn{6}{|c|}{ Emotional and social relationships' health (EMO_SOC) } \\
\hline q0004_0004 & I try to take a positive outlook on things. & 0.839 & \multirow{6}{*}{0.829} & \multirow{6}{*}{0.877} & \multirow{6}{*}{0.547} \\
\hline q0004_0005 & I think positively of life. & 0.818 & & & \\
\hline q0005_0002 & I have good and meaningful relationships with other people. & 0.772 & & & \\
\hline q0005_0001 & I feel close with my family, friends, colleagues and/or neighbors. & 0.719 & & & \\
\hline q0004_0002 & I try to control my emotions. & 0.635 & & & \\
\hline q0004_0003 & At least once a week, I do something just for my own pleasure. & 0.626 & & & \\
\hline \multicolumn{6}{|c|}{ Intellectual health (INTELLECT) } \\
\hline q0006_0002 & I enjoy new experiences and challenges. & 0.876 & \multirow{4}{*}{0.851} & \multirow{4}{*}{0.900} & \multirow{4}{*}{0.692} \\
\hline q0006_0001 & I pursue self-education and self-development continuously. & 0.860 & & & \\
\hline q0006_0003 & I think intellectual challenges are important to my well-being. & 0.847 & & & \\
\hline q0006_0004 & I try to share my good practice and knowledge with others. & 0.738 & & & \\
\hline \multicolumn{6}{|c|}{ Mental health (MENTAL) } \\
\hline q0003_0002 & I try to reduce the level of stress and anxiety. & 0.896 & \multirow{4}{*}{0.824} & \multirow{4}{*}{0.889} & \multirow{4}{*}{0.669} \\
\hline q0003_0003 & I try to control the stress I experience. & 0.857 & & & \\
\hline q0003_0001 & I take some time for relaxation each day. & 0.808 & & & \\
\hline q0003_0004 & I use specific methods to manage the stress I experience. & 0.696 & & & \\
\hline \multicolumn{6}{|c|}{ Physical health (physical activity, nutrition) (PHYSICAL) } \\
\hline q0002_0002 & My daily diet is balanced. & 0.799 & \multirow{4}{*}{0.735} & \multirow{4}{*}{0.835} & \multirow{4}{*}{0.560} \\
\hline q0002_0001 & I exercise and/or practice other physical activities regularly. & 0.784 & & & \\
\hline q0002_0007 & I maintain a healthy body weight. & 0.728 & & & \\
\hline q0003_0005 & I practice yoga or other relaxing workouts at least three times a week. & 0.677 & & & \\
\hline \multicolumn{6}{|c|}{ Avoidance of substances harmful to health (AVOID) } \\
\hline q0002_0004 & I avoid foods with $\mathrm{E}$ additives. & 0.864 & \multirow{4}{*}{0.724} & \multirow{4}{*}{0.832} & \multirow{4}{*}{0.559} \\
\hline q0002_0003 & $\begin{array}{l}\text { I limit the consumption of foods that contain fat, gluten, or } \\
\text { added sugar. }\end{array}$ & 0.791 & & & \\
\hline q0002_0005 & $\begin{array}{l}\text { I worry that there are harmful to health chemicals in the food } \\
\text { I consume. }\end{array}$ & 0.746 & & & \\
\hline q0002_0006 & I restrain myself from consuming alcohol and smoking. & 0.556 & & & \\
\hline & External social relationships & h (EXT_SOC) & & & \\
\hline q0005_0003 & I engage in social, community, or volunteering activities to reduce & 0.898 & & & \\
\hline q0005_0004 & $\begin{array}{l}\text { social exclusion and poverty. } \\
\text { I try to be beneficial to society. }\end{array}$ & 0.898 & 0.753 & 0.893 & 0.806 \\
\hline & Health prevention (1 & ENT) & & & \\
\hline q0002_0009 & I visit a doctor regularly for a preventive health check-up. & 0.800 & & & \\
\hline q0002_0010 & $\begin{array}{l}\text { I monitor my health metrics (like heart rate) every day using a smart } \\
\text { watch a bracelet, or other devices. }\end{array}$ & 0.755 & 0.618 & 0.798 & 0.569 \\
\hline q0002_0008 & I take vitamins and mineral supplements regularly. & 0.705 & & & \\
\hline & Total variance explained by the construct & $65.6 \%$ & & & \\
\hline & KMO & 0.907 & & & \\
\hline
\end{tabular}

The major difference between this result and theoretically distinguished healthy lifestyle domains is that items that were attributed to physical health formed three different factors - physical health (mainly physical activity and nutrition-related items), avoidance of substances harmful to health, and health prevention. This result is logically explained by the multifaceted nature and perception of physical health. Due to the low factorial weights, two measurement items were excluded from the construct structure (q0003_0006 "I try to follow a regular sleep and rest regime" and q0004_0001 "I am able to speak openly about my feelings when angry or worried"). In addition, emotional health items formed one factor together with those items of social health that measured close social relationships with relatives. This indicates that respondents associate emotional health with the quality 
of closest relationships and consider external social relationships as being of different nature and having no impact on emotional state.

To evaluate the construct internal consistency validity and reliability we calculated Cronbach's alpha and composite reliability (CR) coefficients. They demonstrated a rather high level of internal consistency and reliability (Cronbach's alphas ranged from 0.618 to 0.876 , and $C R$ ranged from 0.798 to 0.906 ).

\subsubsection{Self-Organizing Maps}

To identify healthy lifestyles that are dominant in the case of Lithuania, first of all, we employed a self-organizing map (SOM) method. The self-organizing map [59] is an unsupervised learning technique based on an artificial neural network. It is used to visualize high-dimensional data by mapping it into low-dimensional (usually twodimensional) space. Dimension reduction for visualization is also implemented by other methods like multi-dimensional scaling (MDS) or principal component analysis (PCA). These methods present training samples as points on a plane, thus, visually representing a possible cluster structure of samples. In contrast, SOM presents various features of a training sample via colored maps. When comparing several of these feature maps, relationships among features can be understood. These maps also create a topographic intuition about analyzed data, for example, population, which has a high value of stress "lives" in the western side of a dataset, just like similar topographic knowledge that high mountains are on the western side of a country.

The self-organizing maps consist of units (usually visualized using hexagonal cells). Calculations to produce these maps are based on an iterative algorithm. Units are initialized to random feature vectors. In each iteration, observations are assigned to the best matching unit (determined by the most similar feature values) and the unit's feature vectors are recalculated. This procedure is repeated until observations stop moving among the units, that is, until convergence of the algorithm. Later, this observation-to-unit assignment is used to visualize various features. One map visualizes one feature. A map is produced by averaging the feature values of observation for every unit. Units are colored using some palette based on the obtained average values.

The self-organizing map method was recognized by Vesanto and Alhoniemi ([60], p. 586) as especially suitable for the dataset grouping task solving because of its prominent visualization properties. It is still widely used in social sciences after two decades [61-64].

In this research, we used the self-organizing map method to distinguish the healthy lifestyles and visualize their characteristics. This method was chosen because it has excellent visualizations for high-dimensional data. Since the number of SOM units is much higher than the number of clusters, this method discloses more details in the structure of the clusters than other methods. We use SOM with a hexagonal grid containing approximately $5 \sqrt{N}$ total number of units, where $N$ is a sample size (in this case 645 ), as suggested by Vesanto and Alhoniemi [60].

Extracted factors related to different health domains had correlations from weak (0.233 between PREVENT and EMO_SOC) to medium (0.571 between INTELLECT and EMO_SOC). Aiming to represent diverse characteristics of SOM, we included four out of eight factors representing different domains of the healthy lifestyle into the training process based on lower correlations and orthogonality in diagrams of principal component analysis. Since the SOM method is capable of presenting feature maps for both features included in the training of the network and other variables, this also provides one the ability to present maps for the rest factors. There was no need for data scaling because all variables had the same range of values from 1 to 7 .

The network was trained using 1000 iterations and showed convergence after approximately 850 iterations (Figure 1a). The number of sample points per unit (Figure 1b) and distance among neighbor units were quite uniform (Figure 1c) showing a good distribution of data over the network. 


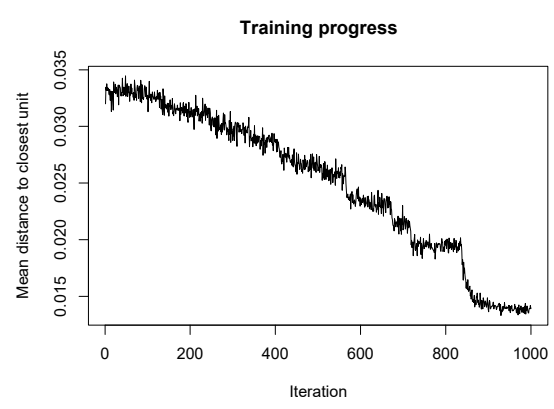

(a)

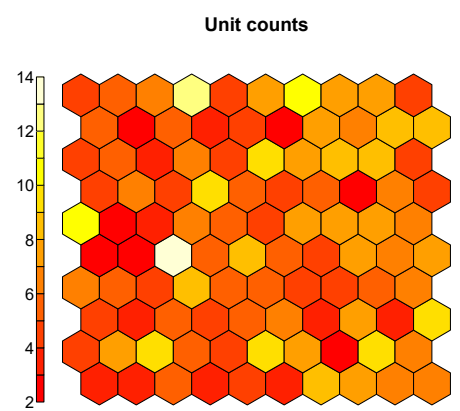

(b)

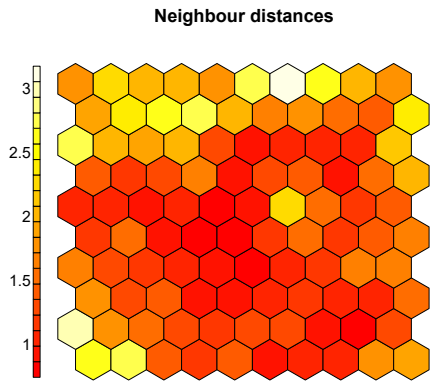

(c)

Figure 1. Network convergence diagnostics: (a) convergence of mean distance to the closest unit over the range of iterations; (b) number of sample points per unit; (c) distances to the neighbor units in the network.

\subsubsection{Clustering}

SOM results can be understood as clustering where each unit corresponds to a different cluster. This approach is hard to interpret because of the too high number of clusters. In order to reduce the number of units obtained from SOM (100 in our case), a k-means clustering method was used. Despite this decision, SOM can be used as a part of the clustering algorithm. A typical approach is to apply k-means clustering to SOM units instead of original sample points. This approach is described by Vesanto and Alhoneiemi [60] and is applied in many research works (e.g., [65-67]).

It is important to notice that preliminary distribution analysis showed that the dataset did not contain clear clusters and multivariate distributions were close to unimodal. Even if natural clusters exist, they highly overlap. Thus, we will interpret clustering results as segments of respondents having some characteristics instead of separate clusters having strict boundaries.

The k-means algorithm was applied to SOM units. Since this iterative algorithm does not ensure global convergence, we used a multiple $(n=100)$ random initialization. The number of clusters was selected using elbow and average silhouette methods. Both elbow method (based on the within-cluster sum of squares (WSS)) (Figure 2a) and average silhouette method (Figure 2b) suggested two to be the optimal number of clusters. This result is not unexpected because our dataset does not have clearly expressed clusters and both methods never select one cluster as an optimal number of clusters. Since all variables had low to medium correlations, we obtained a trivial set of two segments: respondents having a relatively high level of healthy lifestyles (high values in all healthy lifestyle domains) and respondents having a relatively low level of healthy lifestyles (low values in all healthy lifestyle domains).

The second highest value of the average silhouette metrics corresponds to four clusters. A gentle elbow is also noticeable in the WSS plot. Thus, we selected four segments for further analysis to obtain a finer segmentation of respondents in various healthy lifestyle domains. Figure 3 presents the division of the SOM map into segments and visually shows the SOM units attributed to one out of four segments. 


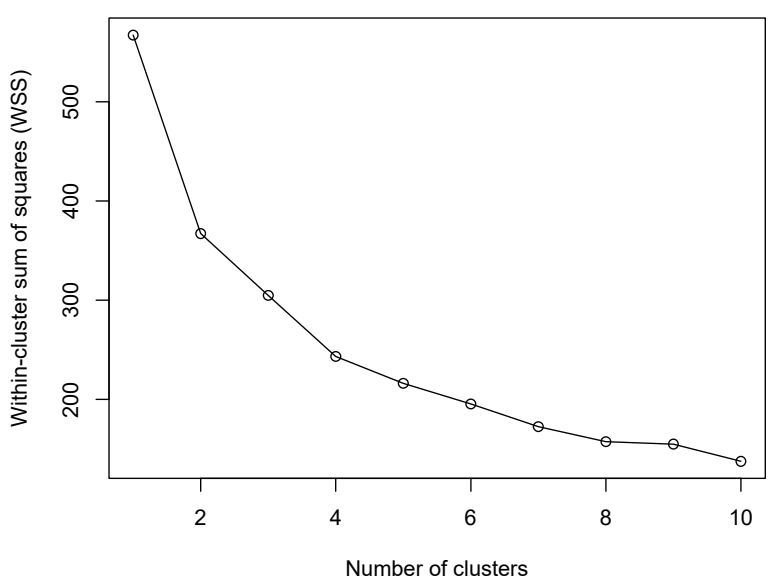

(a)

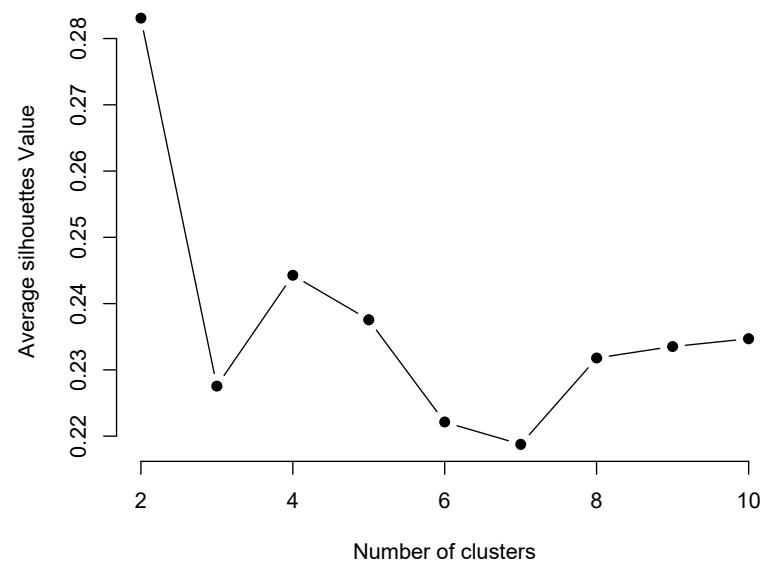

(b)

Figure 2. Suggestion of the number of clusters obtained from the k-means clustering method application for SOM units: (a) within-cluster sum of squares dependency in cluster count for elbow method; (b) average silhuette metrics.

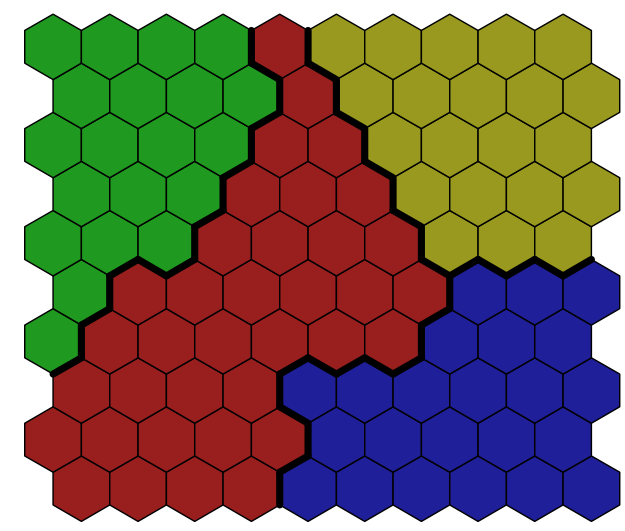

Figure 3. Segments obtained by clustering SOM units.

\subsection{Research Findings}

Maps of segment characteristics obtained by SOM are presented in Figure 4. Each plot in Figure 4 presents a different characteristic of the segment: (a) - spiritual health, (b) - emotional and social relationships' health, etc. Bold lines separate four segments. A color bar next to plots indicates the mapping of feature values into the color of a unit. On most maps, bottom-right corner units have red color, thus persons assigned to SOM units in this corner have a healthier lifestyle in most domains. In a similar way, units next to the top and/or left edges of the maps have a blue color, thus correspond to the lower values, and represent lower levels of health in the particular healthy lifestyle domain. The existence of such a global pattern is consistent with the fact that correlations among all domains are positive. Nevertheless, significant differences in some maps exist. The bottom-left corner contains respondents with a high value of health prevention (see reddish units in Figure 4h), but these persons have lower-than-average values of external social relationships' health (see blueish-green units in Figure 4g). The opposite values, low in health prevention and high in external social relationships' health, have respondents on the top-right corner of the maps. Thus, all four combinations of low/high values of health prevention and external social relationships' health are possible. Respondents of these four types "reside" in the four corners of the maps. The possibility of having different values of this pair of characteristics can also be explained by a weak dependence indicated by a low value of correlation $(r=0.246)$. 


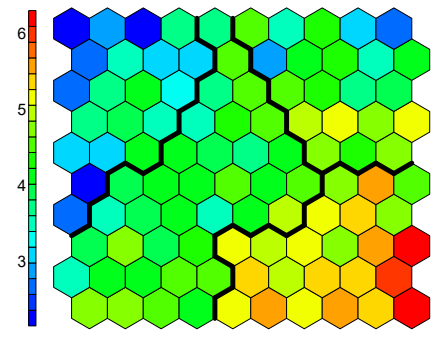

(a)

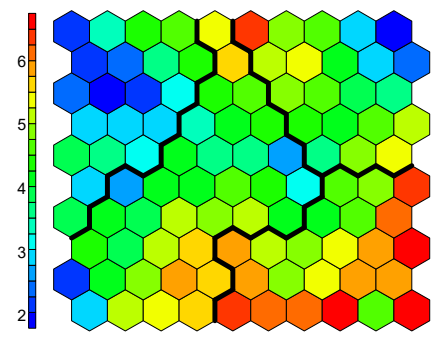

(d)

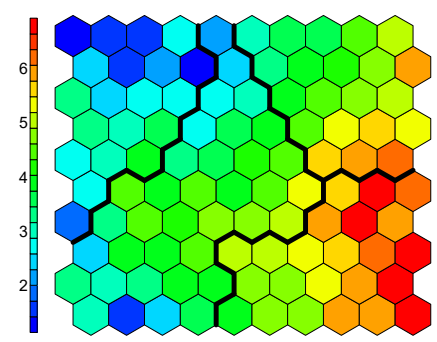

$(\mathrm{g})$

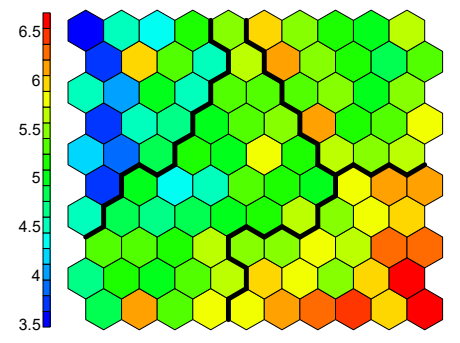

(b)

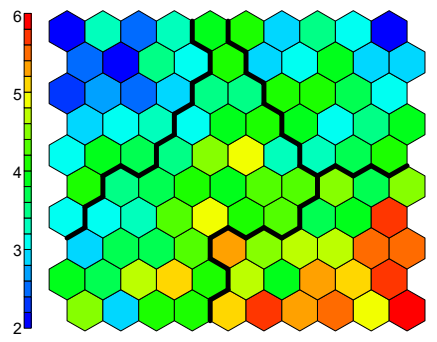

(e)

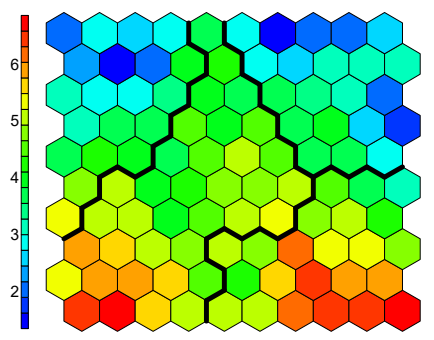

(h)

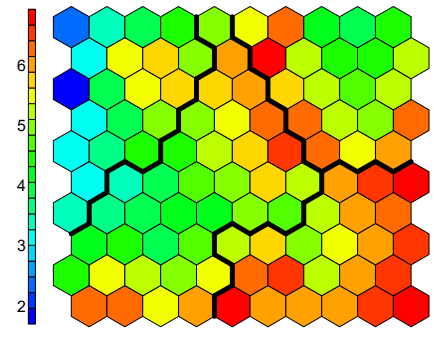

(c)

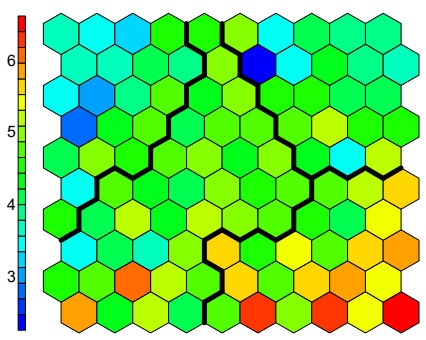

(f)

Figure 4. Maps of segment characteristics: (a) spiritual health (SPIRIT); (b) emotional and social relationships' health (EMO_SOC); (c) intellectual health (INTELLECT); (d) mental health (MENTAL); (e) physical health (physical activity and nutrition) (PHYSICAL); (f) avoidance of substances harmful to health (AVOID); (g) external social relationships' health (EXT_SOC); (h) health prevention (PREVENT).

The different relationship is observed for a pair of emotional and social relationships and intellectual health. The emotional and social relationships' health map (see Figure $4 \mathrm{~b}$ ) is a little noisy but both maps have the same pattern-reddish values at the bottom and right edges, especially at the bottom-right corner, and blueish values at the top half of left edge of the map and a slated yellow-reddish region from the bottom-right corner to the middle of the top edge. This indicates that the values of these two domains are quite similar. This is confirmed with the highest correlation coefficient found in the sample $(r=0.571)$.

To describe the indicated four segments for their healthy lifestyle domains, we used SOM results presented in Figure 4 and the scale of red, green and blue colors. Based on that, we created new variables having only three values, where 1 indicated low levels of the particular healthy lifestyle domain, 2 indicated medium levels and 3-high levels of the particular healthy lifestyle domain. These results are presented in Table 3. 
Table 3. Reflection of healthy lifestyle domains in different segments.

\begin{tabular}{|c|c|c|c|c|c|c|c|c|c|}
\hline $\begin{array}{c}\text { Segment } \\
\text { No. }\end{array}$ & & SPIRIT & EMO_SOC & INTELLI & MENTAL & PHYSICAL & AVOID & EXT_SOC & PREVENT \\
\hline \multirow[t]{2}{*}{1} & Mean & 2.465 & 2.885 & 2.930 & 2.739 & 2.535 & 2.522 & 2.681 & 2.484 \\
\hline & $\mathrm{N}$ & 157 & 157 & 157 & 157 & 157 & 157 & 157 & 157 \\
\hline \multirow[t]{2}{*}{2} & Mean & 1.897 & 2.277 & 2.420 & 2.018 & 2.058 & 2.245 & 1.732 & 2.277 \\
\hline & $\mathrm{N}$ & 224 & 224 & 224 & 224 & 224 & 224 & 224 & 224 \\
\hline \multirow[t]{2}{*}{3} & Mean & 1.913 & 2.530 & 2.571 & 1.953 & 1.765 & 1.879 & 2.222 & 1.383 \\
\hline & $\mathrm{N}$ & 149 & 149 & 149 & 149 & 149 & 149 & 149 & 149 \\
\hline \multirow[t]{3}{*}{4} & Mean & 1.365 & 1.687 & 1.783 & 1.409 & 1.487 & 1.765 & 1.165 & 1.548 \\
\hline & $\mathrm{N}$ & 115 & 115 & 115 & 115 & 115 & 115 & 115 & 115 \\
\hline & \multicolumn{9}{|c|}{$\begin{array}{c}\text { Highest mean value in responses } \\
\text { The second highest mean value in responses } \\
\text { The third highest mean value in responses } \\
\text { The lowest mean value in responses }\end{array}$} \\
\hline
\end{tabular}

Note: Value calculation is based on SOM results, according to such an algorithm: RECODE INTELLECT_M, MENTAL_M, SPIRIT_M, AVOID_M $(1$ thru $3.6=1)(3.61$ thru $5.2=2)(5.21$ thru $7=3)$ INTO INTELLECT_1, MENTAL_1, SPIRIT_1, AVOID_1. RECODE EXT_SOC_M, PREVENT_M $(1$ thru $3=1)(3.01$ thru $5.2=2)(5.21$ thru $7=3)$ INTO EXT_SOC_1, PREVENT_1. RECODE EMO_SOC_M $(1$ thru $4.5=1)$ $(4.51$ thru $5.2=2)(5.21$ thru $7=3)$ INTO EMO_SOC_1.

Based on the findings in Table 3 the following four segments emerged and they are titled and described as follows:

1. Healthy lifestyle guru ( $24 \%$ of the respondents). I pay a lot of attention to my health and maintain a healthy lifestyle. I am physically active, monitor my physical health and avoid unhealthy substances/foods. I try to reduce anxiety and stress levels, and I find time to relax and rest. I care about my intellectual and spiritual health, maintain strong social ties with relatives and friends; I try to be a citizen.

2. Physical-health-oriented ( $35 \%$ of the respondents). I pay quite a lot of attention to my health and healthy lifestyle. My level of physical activity is above average; I pay quite a lot of attention to disease prevention and avoid consumption of unhealthy substances/foods. Sometimes I find it hard to avoid stress and anxiety, relax, and manage emotions. I pay less attention to fostering spiritual, intellectual health and social connections.

3. Mental well-being-oriented ( $23 \%$ of the respondents). I pay quite a lot of attention to my health and a healthy lifestyle. The most important aspects of health for me are related to a good psychological condition, positive emotions, fostering spirituality and pleasant intellectual activities. Relationships with loved ones and friends affect my health. I am relatively physically active, unable to limit the use of unhealthy substances/foods, avoid stress and spend time on health prevention.

4. Unhealthy lifestyle representatives ( $18 \%$ of the respondents). I pay too little attention to my health and healthy lifestyle. It is difficult for me to maintain not only physical but also psychological, emotional and spiritual health. I try to focus on disease prevention, but I find it difficult to avoid the use of unhealthy substances/foods, stress and anxiety. Sometimes I find it challenging to maintain good social relationships with loved ones and friends.

We also attempted to identify a demographic profile representative for each segment. For example, we drew SOM maps for age and an average personal income level per month by using middle values of predetermined intervals (five in the case of age and seven in the case of income level) (see Figure 5). 


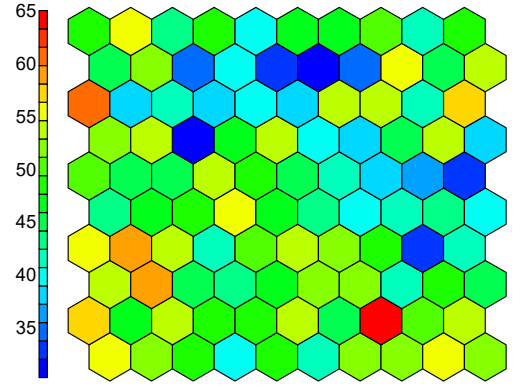

(a)

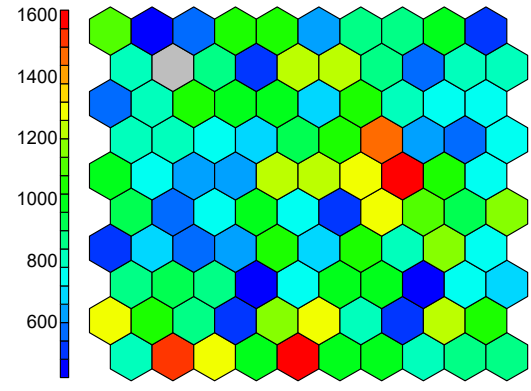

(b)

Figure 5. Maps of characteristics for (a) age group and (b) average personal income level per month.

As seen in Figure 5, we obtained quite noisy maps. The maps indicate that neither age nor income determines the healthy lifestyle segment of the respondent. Correlation of age $(r=-0.141 \ldots+0.172)$ and income $(r=-0.085 \ldots+0.216)$ to other healthy lifestyle domains is also low. This indicates that the healthy lifestyles segment is not predetermined by the socio-demographic profile of a consumer.

\section{Discussion}

With this study, we sought to (1) adapt a measurement scale for the healthy lifestyle measurement in a non-English speaking country and integrate items that have recently emerged and became of high relevance to consumers; (2) identify representative components of healthy lifestyles among consumers; (3) apply a novel SOM method that allows to segment the market using healthy lifestyles of consumers. The study contributes to the current body of literature by offering an insight into the healthy lifestyle-based segments of consumers and develops an instrument to measure healthy lifestyles.

First, based on the existing scales in the literature, the study has developed a healthy lifestyle measurement scale and validated it in the context of a non-English speaking country. The findings of the study suggest that the scale is reliable and can be (a) used to measure the healthy lifestyles of consumers and (b) applied as a market segmentation instrument by marketing companies doing business in the sector of health-related products and services. The study reveals that a healthy lifestyle is multidimensional: eight different factors were extracted based on the data from 645 consumers in the context of Lithuania. The multidimensional healthy lifestyle construct consists of the following eight dimensions: (a) spiritual health, (b) emotional and social relationships' health, (c) intellectual health, (d) mental health, (e) physical health, (f) avoidance of substances harmful to health, $(\mathrm{g})$ external social health and $(\mathrm{h})$ health prevention. While previous scales found in the literature were unidimensional and were mainly developed and tested in an Englishspeaking environment [26], the refined and up-to-date healthy lifestyle scale in this study appears to be multidimensional and reflects the richness of items used to measure healthy lifestyle of consumers in a non-English speaking country. This measurement scale has established and verified eight dimensions that allow us to better understand the healthrelated decision-making of consumers. The eight dimensions of the healthy lifestyle scale are discussed below.

The first dimension of the healthy lifestyle measurement scale refers to "spiritual health". Specifically, consumers perceive "spiritual health" as sharing their love and peace with other individuals, feeling that nurturing their spirituality is important and they understand the meaning of life. This is in line with earlier research indicating that love, peace and spirituality are very important in maintaining spiritual health [33].

The next dimension of the healthy lifestyle measurement scale is entitled "health of emotional and social relationships". Consumers express "health of emotional and social relationships" through taking a positive outlook on events, positive thinking about life, and meaningful relationships with other people, friends and family members and control 
of emotions. This is in line with previous research suggesting that social networking is an important part of psychological wellbeing [30].

The following dimension of the healthy lifestyle measurement scale refers to intellectual health". Consumer "intellectual health" is perceived as enjoyment of new experiences and challenges, continuous pursuit of new ideas and self-education and sharing knowledge with other people. Again, this dimension is in line with previous studies suggesting that new experiences and challenges positively contribute to the healthy lifestyle of consumers [10].

The fourth dimension of the healthy lifestyle measurement scale title "mental health" is recognized as an ability to stress less, relax each day and manage anxiety. This is in line with previous studies suggesting that emotions and the ability to manage stress influence healthy lifestyles $[13,28]$ and satisfaction with life positively influence mental health $[29,68]$.

The fifth healthy lifestyle measurement scale dimension of "physical health" is expressed through a daily balanced diet, physical exercise and healthy body weight. This is similar to Wardle and Steptoe [12] and Kim and Kang [13] who state that healthy lifestyles should become a norm among consumers consuming organic food, cooking healthy meals and following healthy diets for the rest of their lives.

The following dimension of the healthy lifestyle measurement scale entitled "avoidance of substances harmful to health" is perceived by consumers as avoiding foods with additives, fat, gluten and added sugar or health chemicals. Consumers also attempt to avoid alcohol and smoking. This dimension could be linked to previous studies suggesting that the reduction of harmful substances increases the lifetimes and enjoyment of the healthy life of consumers (e.g., [22,23]).

The seventh dimension of the healthy lifestyle measurement scale refers to "external social health". This dimension is described as an engagement in volunteering activities with an aim to contribute to society. This finding is in line with previous studies stating that selfidentity and self-actualization can be achieved through healthy lifestyle domains [14,34].

The last dimension of the healthy lifestyle measurement scale is titled "health prevention" and is related to regular visits to GP for a health checkup, consuming food supplements and monitoring one's health through digital devices. This healthy lifestyle measurement scale dimension may be in line with a previous study by O'Donoghue et al. [42,43] stating that consumers who adopt healthy lifestyles tend to seek advice from therapists regarding physical activities that improve the physical health of individuals. This also may be linked to previous studies by Chen [41], Tindle et al., [44] and Uzzan et al. [40] who suggested that those consumers who want to stay healthy use supplements to reduce illnesses because such foods contribute to the reduction of illnesses and improve the healthy lifestyles of consumers.

Second, the study is one of the first attempts to utilize the SOM method in the healthy lifestyles and consumer behavior literature as it allows for differentiation of consumers into several segments based on healthy lifestyle domains that individuals lead and provides a visual representation of their manifestation. A self-organized maps method was used in research on various topics in social sciences, but it has not been used in research on healthy lifestyles. A successful application of the method in a novel domain demonstrates that this method is still underestimated and can be used to enrich data insights in a wider range of clustering and segmentation problems.

We should notice that many of the feature maps obtained in this study are quite similar. Clustering used on SOM units also found segments with a majority of healthy lifestyle features having high (segment 1), medium (segments 2 and 3), and low values (segment 4). The method failed to find segments with distinctly high values of healthy lifestyle in some domains and distinctly low values in other domains. Nevertheless, we should not interpret this as a limitation of the method, but rather a limitation of the self-reported research based on the questionnaire survey (see more in the section of limitations). The feature maps of spiritual health, emotional and social relationship health and physical health (Figure $4 a-c$ ) are very similar. This is consistent with the fact that these variables are highly correlated. 
As mentioned before, the study identified four segments. Those four segments are titled as follows: (1) health guru (24\%); (2) physical health promoters (35\%); (3) oriented towards psychological wellness (23\%) (4) representatives of unhealthy lifestyle (18\%).

The largest segment is related to the "physical health promoters" and comprises 35\% of consumers in Lithuania. This is a novel segment that has emerged from the findings and is starting to appear in Lithuania. No previous studies in the literature reported such segments with consumers having such a different approach to adopting a healthy lifestyle with rather high levels of physical activity but low levels of spiritual and intellectual health of consumers.

The second segment comprises $24 \%$ of Lithuanian consumers and those consumers can be entitled as "gurus of health". This segment of consumers might be comparable to the US consumer segment who consume a lot of green products in the market and are early adopters of new products related to their healthy lifestyles [51,53], but our study did not examine the levels of consumer innovativeness when adopting a healthy lifestyle.

The following segment of consumers is "oriented towards psychological wellness" and comprises $23 \%$ of Lithuanian individuals. This consumer segment is similar to the clusters previously identified in the literature. For example, Picha and Navratil [9] suggested that this type of cluster can be identified from the specific consumer behavior which is linked to their healthy lifestyles.

The final consumer segment refers to a group of "unhealthy consumers" in terms of their engagement in adopting healthy lifestyles and comprises $18 \%$ of individuals. This segment is similar to the cluster identified by Picha and Navratil [9], who suggested that consumers did not follow the healthy lifestyle path in one out of three segments identified in their study.

Overall, our study finds that three segments are similar to the ones reported in earlier studies (e.g., [9,51]), however, our study has uncovered a very unique and interesting segment of "physical health promoters" which has not yet been offered in the literature. Our study offers a novel consumer segment with a thorough characterization of this distinctive healthy lifestyle consumer type.

\section{Marketing Implications}

There are several policy and marketing implications for the industry of health products. First, the study offers a validated and up-to-date scale to measure the healthy lifestyles of consumers. This measurement scale would be valuable for marketers and entrepreneurs operating in the health product sector to apply it as a market segmentation tool and measure the health behavior of their target audiences aiming to identify their healthy living habits. Based on this information, companies could further segment their market and develop tailored marketing communications campaigns to attract consumer attention to their health brands, health products and services and utilize marketing communications budget optimally by promoting those health aspects that matter most in each segment.

Second, four novel segments were identified among consumers based on how they lead their health-related life; marketers could use these segments as a starting point for their marketing-related activities in the health product market. That is, marketers could use those segments to promote their healthy lifestyle-related services, products and brands by customizing their marketing communications activities for each segment to adequately meet the needs of those consumers. Further, knowing the specific characteristics of the target audience, marketers could review the current budget of their marketing communications strategy and adjust it with the aim to improve the resource allocation and improve the value of the company's health brands communicated to the target audiences.

For example, the first consumer segment of "health gurus" already takes care of their health and this segment shows a commendable way of following their healthy style of life. Therefore, there is very little need for interference from marketers. The marketing efforts in this segment would be only linked to the encouragement to continue living such an admirable life and providing this segment with information about existing and new 
products and services that enter the market and praising them for their efforts to maintain such a healthy lifestyle in the company's communications with their customers.

A completely different marketing communications strategy would apply to the other segment of consumers who are "oriented towards psychological wellness". The company could organize events and invite dietitians to inform consumers of these segments about potential negative consequences of a sedentary lifestyle, such as diabetes, heart attack and other long-term illnesses linked to the lack of physical exercise. The companies could promote their products and services that are linked to the care of physical health rather than emotional health.

Contrary to the third segment which is "oriented towards psychological wellness", the second segment of "physical health promoters" would require a very different approach with the emphasis of marketing communications on the mental and emotional health of individuals. The segment of "physical health promoters" suffers from the inability to manage their emotions, thus it would be beneficial for the companies to organize events and invite counselors or psychologists who could educate consumers about emotion management that will ultimately lead to increased perceptions about their wellbeing and the need to take care after their emotional health. During those events, companies could also advertise products and services related to mental health wellness, such as classical music or yoga that positively contribute to the care of mental health. Companies could also employ social media influencers (e.g., nano or micro celebrities) to advertise their products and services in an online environment [69]. Social media influencers are considered experts in their field; they are perceived by consumers as both trustworthy and credible sources of information and can therefore contribute to the promotion of the company's health brands.

Finally, marketers may attempt and design a marketing communications strategy for the final segment of individuals who do not adopt healthy lifestyles at all. Although the study did not investigate the motives behind such behavior, it is likely that these consumers are not interested in sustaining healthy lifestyles or they think they do not have the means to adopt such a lifestyle. Thus, events that trigger curiosity would be beneficial to this group of consumers. A combination of conference-style or other events with celebrities and experts in the field such as psychologists, general practitioners and dietitians explaining the benefits of mental health and physical body care and well-being to individuals may contribute to their behavioral change. Specific information workshops with brochures could be designed and distributed, emphasizing the importance of health for the overall well-being of an individual. Tailored products and services could be offered to support those claims. Curiosity is well satisfied through testing products and services that are on offer to live healthier lives, thus companies could offer their services and products to try for this consumer segment before they make up their minds about the willingness to acquire such products. By raising awareness of consumers about health-related issues and providing information about products and services that might contribute to the solution of health problems, companies gain important information for the development of marketing communications strategies to encourage consumers to adopt healthier lifestyles. However, such significant behavioral changes do not happen immediately, and it is difficult to achieve and maintain them during a prolonged period of time, therefore, intervention from public policymakers to initiate and continue the education of this consumer segment is crucial.

Third, based on the findings of the study, age and income hardly determine the segments of a healthy lifestyle of consumers, but their way of life does. Since it is easier to change one's lifestyle than personal values or initial beliefs [70], thus, public policymakers could use this information to educate consumers about the importance of their health and persuade them to be self-determined and change their lifestyles with particular focus on the fourth segment of consumers leading unhealthy lifestyles. Additionally, the focus of attention should also be the individuals comprising the other segments where consumers care less about their mental health compared to their physical health and vice versa. Offering information and knowledge about healthy lifestyles, physical exercise and their positive effect on the individual's well-being and improved quality of life, and other wider societal 
and economic benefits, such as reduced national healthcare bills and longer life expectancy of individuals, can positively contribute to the changes in the mentality of individuals who belong to the segments identified in the study. Through the anticipated behavioral change, public policymakers would aim to reduce the size of an "unhealthy lifestyle" consumer segment. It is expected that interventions, which public policymakers will design and implement for the consumers with "unhealthy lifestyles" will have a spillover effect on the other three segments and will support the existing motivation of consumers who belong to the other three segments to continue leading healthy lifestyles and focus on both their body and their emotions. Such implementations by public policymakers would offer a broader societal and economic impact.

\section{Conclusions}

The study's results offer two key outcomes. First, it focuses on developing an updated measurement scale of the healthy lifestyles of consumers and tests it in the context of Lithuania, which is a non-English speaking country. The study concludes that the scale produces reliable results, the construct is multidimensional and can be used to measure healthy lifestyles of consumers. The measurement scale enables marketers to better understand the dimensionality of the health of their target consumers and this information can be used (a) to segment the market of companies operating in the sector of health products; (b) to customize their marketing activities based on the consumer health profile; (c) to allocate marketing communications budget/financial resources optimally.

Second, the paper utilizes a novel SOM method in the marketing and healthy lifestyle domain to identify four clusters of consumers who adopt different healthy lifestyles, namely, (a) health guru, (b) physical health promoters, (c) oriented towards psychological wellness and (d) representatives of an unhealthy lifestyle. The study has identified that the segment of "physical health promoters" can be considered novel and unique to this context since no previous studies provided such findings. Further, the study demonstrates that health issues are important among consumers in Lithuania and that majority of consumers tend to lead a healthy lifestyle with varying levels of physical, spiritual and intellectual health. The study suggests that there is a tendency among consumers to perceive the importance of physical health as more critical to look after while spiritual, emotional and mental health are less taken care of by consumers in Lithuania.

Overall, the findings of this study offer important guidelines for marketers and public policymakers, which will aid in gaining a better understanding of consumer healthrelated decision-making. The four segments identified in this study are very useful for companies operating in the market of Lithuania and for public policymakers. Marketers can target specific groups of consumers with their health-related brands. Tailored marketing communications campaigns can be directed at four different segments of consumers with specific aims to be achieved and matching products to be offered to those targeted groups in each segment. Public policymakers could target those four segments of consumers with customized educational information on the benefits of healthy lifestyles to their wellbeing and increased quality of life as well as other societal and economic benefits.

\section{Limitations and Further Research Directions}

The study has several limitations that offer future research directions. First, the updated healthy lifestyle measurement scale has only been tested in one small and nonEnglish speaking country, and thus warrants further investigation in larger economies with different languages and multicultural environments where large groups of consumers represent different cultures while living in one country such as China or the USA. Given the importance of the cultural context [71], the dimensionality of the measurement scale might differ.

Second, the SOM method has not yet been applied to segment consumers based on their healthy lifestyles in the sustainability and consumer behavior literature. The results of this study contradict previous research by Divine and Lepisto [19] who state that older 
and more educated females tend to adopt healthy lifestyles. Our study suggests that sociodemographic profile does not predict the healthy lifestyle segment of consumers. Although the empirical study has been conducted with adult respondents in a small country, the application of the SOM method to identify identical segments of healthy lifestyles needs to be further verified empirically across different cultural contexts.

Third, social desirability bias [72] is an important aspect of all studies that rely on self-reported data since the data reflects not true actual behavior but socially desirable behavior. Social desirability bias requires consideration in further studies since respondents' self-reported answers in this study when responding to questionnaires during the data collection process may lead to biased findings. However, it was the only feasible option in this study to collect the data through questionnaires since the study aimed to develop the measurement scale and the market segmentation instrument.

Fourth, this study only measured the attitudes of individuals and did not examine the nature of motivations for adopting (or not adopting) their healthy lifestyles, personality traits and their initial beliefs. Those factors influence consumer attitudes and behavior. Therefore, it would be interesting to further investigate consumers in a qualitative study where initial beliefs and the nature of motives would be uncovered (for example, moral obligations, health issues, financial constraints, convenience/accessibility of fresh food) and such information would aid the development of a research model comprising healthy lifestyle antecedents to be further tested empirically. This information would allow formulating very specific recommendations for marketing practitioners and policymakers, such as organizing various sports events and competitions, offering discounts, vouchers or other forms of rewards when attending a gym or riding a bike in town or exercising in mountains and renting ski equipment.

Fifth, our study did not examine the levels of individual innovativeness when adopting a healthy lifestyle, thus future research needs to consider innovativeness [73] as it contributes to the speed by which consumers adopt new products and services. One of the reasons for such a large (18\%) "unhealthy lifestyles" consumer segment might be their unwillingness to change their current convenient lifestyles and adopt an innovative approach to their living.

Sixth, future research may focus on the links between healthy lifestyles identified in this study and sustainable consumption. Taking into consideration the critique of existing research when discussing the construct of sustainable consumption, it is recommended to highlight ethical and technological dimensions in the context of sustainable consumption and prioritize the perspective of responsible consumption.

Author Contributions: Conceptualization, J.B., A.G., A.D. and Ž.P.; methodology, A.G., J.B., A.D. and Ž.P.; validation, A.G., A.D. and J.B.; formal analysis, A.G. and M.K.; investigation, A.G., J.B., A.D. and Ž.P.; data curation, A.G., J.B., A.D., Ž.P. and M.K.; Writing-Original draft preparation, A.G., L.Š., A.D., M.K. and J.B.; Writing-Review and Editing, A.G., J.B., A.D. and L.Š.; visualization, A.G. and M.K.; supervision, J.B., A.G. and A.D.; project administration, J.B.; funding acquisition, J.B. and A.G. All authors have read and agreed to the published version of the manuscript.

Funding: This project has received funding from the Research Council of Lithuania (LMTLT), agreement No [S-MIP-20-10].

Informed Consent Statement: Informed consent was obtained from all subjects involved in the study.

Data Availability Statement: The data presented in this study are available on request from the corresponding author from 1 December 2022. The data are not publicly available due to overuse and uncertainties. [dataset] Gadeikienè, A.; Banytè, J.; Dovalienè, A.; Piligrimienè, Ž. \& Vaičiukynaitè, E. (2021). Data of Healthy Lifestyle Research: a case of Lithuanian Consumers. Zenodo. http:// doi.org/10 .5281 /zenodo.5062112 (accessed on 1 September 2021).

Conflicts of Interest: The authors declare no conflict of interest. The funders had no role in the design of the study; in the collection, analyses, or interpretation of data; in the writing of the manuscript, or in the decision to publish the results. 


\section{References}

1. Mintel.com. Global Consumer Trends 2030. 2020. Available online: https:/ /www.mintel.com/global-consumer-trends-2030/ (accessed on 23 March 2021).

2. Westbrook, G.; Angus, A. TOP10 Global Consumer Trends 2021. Euromonitor International, 2021; pp. 1-47. Available online: https:/ / go.euromonitor.com/white-paper-EC-2021-Top-10-Global-Consumer-Trends.html\#download-link/ (accessed on 17 March 2021).

3. Cohen, M.J. Does the COVID-19 outbreak mark the onset of a sustainable consumption transition? Sustain. Sci. Pract. Policy 2020, 16, 1-3. [CrossRef]

4. Euromonitor. Health and Nutrition Trends: Seeking a Healthy Life. 2020. Available online: https://blog.euromonitor.com/ health-and-nutrition-trends-seeking-a-healthy-life/ (accessed on 17 March 2021).

5. Scholderer, J.; Brunso, K.; Bredahl, L.; Grunert, K.G. Cross-cultural validity of the food-related lifestyles instrument (FRL) within Western Europe. Appetite 2004, 42, 197-211. [CrossRef]

6. Jensen, M. Defining lifestyle. Environ. Sci. 2007, 4, 63-73. [CrossRef]

7. Furman, A.; Maison, D.; Sekscinska, K. Segmentation based on attitudes toward corporate social responsibility in relation to demographical variables and personal values-Quantitative and qualitative study of Polish consumers. Front. Psychol. 2020, 11, 450. [CrossRef] [PubMed]

8. Lubowiecki-Vikuk, A.; Dąbrowska, A.; Machnik, A. Responsible consumer and lifestyle: Sustainability insights. Sustain. Prod. Consum. 2021, 25, 91-101. [CrossRef] [PubMed]

9. Picha, K.; Navratil, J. The factors of lifestyle and sustainability influencing pro-environmental buying behavior. J. Clean. Prod. 2019, 234, 233-241. [CrossRef]

10. Apostu, M. New points of view on concept of health and lifestyle. Procedia-Soc. Behav. Sci. 2013, 92, 50-54. [CrossRef]

11. Matharu, M.; Jain, R.; Kamboj, S. Understanding the impact of lifestyle on sustainable consumption behavior: A sharing economy perspective. Manag. Environ. Qual. Int. J. 2020, 32, 20-40. [CrossRef]

12. Wardle, J.; Steptoe, A. Socioeconomic differences in attitudes and beliefs about healthy lifestyles. J. Epidemiol. Community Health 2003, 57, 440-443. [CrossRef]

13. Kim, C.H.; Kang, K.A. The validity and reliability of the Healthy Lifestyle Screening Tool. Phys. Ther. Rehabil. Sci. 2019, 8, 99-111. [CrossRef]

14. Evans, D.; Abrahamse, W. Beyond rhetoric: The possibilities of and for sustainable lifestyles. Environ. Pollut. 2009, 18, 486-502. [CrossRef]

15. Lorenzen, J.A. Going green: The process of lifestyle change. Sociol. Forum 2012, 27, 94-116. [CrossRef]

16. Thogersen, J. Sustainable food consumption in the nexus between national context and private lifestyle: A multi-level study. Food Qual. Prefer. 2017, 55, 16-25. [CrossRef]

17. Lim, W.M. Inside the sustainable consumption theoretical toolbox: Critical concepts for sustainability, consumption, and marketing. J. Bus. Res. 2017, 78, 69-80. [CrossRef]

18. Lim, W.M. A blueprint for sustainability marketing: Defining its conceptual boundaries for progress. Mark. Theory 2016, 16, 232-249. [CrossRef]

19. Divine, R.L.; Lepisto, L. Analysis of the healthy lifestyle consumer. J. Consum. Mark. 2005, 22, 275-283. [CrossRef]

20. Yap, S.F.; Othman, M.N. Marketing to Healthy Lifestyle Consumers: An Analysis of Demographic and Social Cognitive Factors. Asia Pac. Manag. Rev. 2010, 15, 601-618. [CrossRef]

21. Choi, S. LOHAS Scale Development and Validation. Ph.D. Thesis, Purdue University, West Lafayette, IN, USA, 2020.

22. Hanawi, S.A.L.; Saat, N.Z.M.; Zulkafly, M.; Hazlenah, H.; Taibukahn, N.H.; Yoganathan, D.; Abdul Rahim, N.N.; Mohd Bashid, N.A.A.; Abdul Aziz, F.A.; Low, F.J. Impact of a healthy lifestyle on the psychological well-being of university students. Int. J. Pharm. Res. Allied Sci. 2020, 9, 1-7.

23. Maenhout, L.; Peuters, C.; Cardon, G.; Copernolle, S.; Crombez, G.; DeSmet, A. The association of healthy lifestyle behaviors with mental health indicators among adolescents of different family affluence in Belgium. BMC Public Health 2020, 20, 958-972. [CrossRef]

24. Taymoori, P.; Moeini, B.; Lubans, D.; Bharami, M. Development of psychometric testing of the adolescent healthy lifestyle questionnaire. J. Educ. Health Promot. 2012, 1, 20. [CrossRef]

25. Isakadze, N.; Martin, S.S. How useful is the smartwatch ECG? Trends Cardiovasc. Med. 2020, 30, 442-448. [CrossRef]

26. Choi, S.; Feinberg, R.A. The LOHAS (Lifestyle of Health and Sustainability) Scale Development and Validation. Sustainability 2021, 13, 1598. [CrossRef]

27. Balanzá-Martínez, V.; Kapczinski, F.; de Azevero Cardoso, T.; Atienza-Carbonell, B. The assessment of lifestyle changes during the COVID-19 pandemic using a multidimensional scale. Rev. Psiquiatr. Salud Ment. 2021, 14, 16-26. [CrossRef] [PubMed]

28. Trigueros, R.; Aguilar-Parra, J.M.; Cangas, A.J.; Bermejo, R.; Ferrandiz, C.; Lopez-Liria, R. Influence of emotional intelligence, motivation and resilience on academic performance and the adoption of healthy lifestyle habits among adolescents. Int. J. Environ. Res. Public Health 2019, 16, 2810. [CrossRef] [PubMed]

29. Nedly, N.; Ramirez, F.E. Emotional health and stress management. In Lifestyle Medicine, 3rd ed.; Rippe, J.M., Ed.; CRC Press: Boca Raton, FL, USA, 2019. [CrossRef] 
30. Lara, J.; Godfrey, A.; Evans, E.; Heaven, B.; Brown, L.J.; Barron, E.; Rochester, L.; Meyer, T.D.; Mathers, J.C. Towards measurement of the Healthy Ageing Phenotype in lifestyle-based intervention studies. Maturitas 2013, 76, 189-199. [CrossRef] [PubMed]

31. Becker, C.M.; Moore, J.B.; Whetstone, L.; Glascoff, M.E.; Chaney, E.; Felts, E.; Anderson, L. Validity evidence for the salutogenic wellness promotion scale. Am. J. Health Behav. 2009, 33, 455-465. [CrossRef] [PubMed]

32. Scheer, S.B.; Lockee, B.B. Addressing the wellness needs of online distance learners. Open Learning. Open Learn. J. Open Distance e-Learn. 2003, 18, 177-196. [CrossRef]

33. Boswell, G.H.; Kahana, E.; Dilworth-Anderson, P. Spirituality and healthy lifestyle behaviors: Stress counter-balancing effects on the well-being of older adults. J. Relig. Health 2006, 45, 587-602. [CrossRef]

34. Sadat Hoseini, A.S.S.; Razaghi, N.; Panah, A.H.K.; Nayeri, N.D. A concept of spiritual health. J. Relig. Health 2019, 58, 1025-1046. [CrossRef]

35. Park, H.H. The influence of LOHAS consumption tendency and perceived consumer effectiveness on trust and purchase intention regarding upcycling fashion goods. Int. J. Hum. Ecol 2015, 16, 37-47. [CrossRef]

36. Hustvedt, G.; Peterson, H.H.; Chen, Y.J. Labelling wool products for animal welfare and environmental impact. Int. J. Consum. Stud. 2008, 32, 427-437. [CrossRef]

37. Kim, H.Y.; Chung, J.E. Consumer purchase intention for organic personal care products. J. Consum. Mark. 2011, 28 , 40-47. [CrossRef]

38. Essoussi, L.H.; Zahaf, M. Decision making process of community organic food consumers: An exploratory study. J. Cons. Mark. 2008, 25, 95-104. [CrossRef]

39. Kim, M.J.; Lee, C.K.; Kim, W.G.; Kim, J.M. Relationships between lifestyle of health and sustainability and healthy food choices for seniors. Int. J. Contemp. Hosp. Manag. 2013, 25, 558-576. [CrossRef]

40. Uzzan, M.; Nechrebeki, J.; Labuza, T.P. Thermal and storage stability of nutraceuticals in a milk beverage dietary supplement. J. Food Sci. 2007, 72, 109-114. [CrossRef] [PubMed]

41. Chen, M.F. The joint moderating effect of health consciousness and healthy lifestyle on consumers' willingness to use functional foods in Taiwan. Appetite 2011, 57, 253-262. [CrossRef] [PubMed]

42. O'Donoghue, G.; Cunningham, C.; Murphy, F.; Woods, C.; Aagaard-Hansen, J. Assessment and management of risk factors for the prevention of lifestyle-related disease: A cross-sectional survey of current activities, barriers and perceived training needs of primary care physiotherapists in the Republic of Ireland. Physiotherapy 2014, 100, 116-122. [CrossRef] [PubMed]

43. O’Donoghue, G.; Kennedy, A.; Puggina, A.; Aleksovska, K.; Buck, C.; Burns, C.; Cardon, G.; Carlin, A.; Ciarapica, D.; Colotto, M.; et al. Socio-economic determinants of physical activity across the life course: A "DEterminants of DIet and Physical ACtivity" (DEDIPAC) umbrella literature review. PLoS ONE 2018, 13, e0190737. [CrossRef]

44. Tindle, H.A.; Davis, R.B.; Phillips, R.S.; Eisenberg, D.M. Trends in use of complementary and alternative medicine by US adults: 1997-2002. Altern. Ther. Health Med. 2005, 11, 42-49.

45. Lee, I.C.; Chang, C.S.; Du, P.L. Do healthier lifestyles lead to less utilization of healthcare resources? BMC Health Serv. Res. 2017, 17, 243. [CrossRef]

46. Küçük, E. Health perception and healthy lifestyle behaviors of female factory workers. Arch. Environ. Occup. Health 2016, 71, 216-221. [CrossRef] [PubMed]

47. Kudubes, A.A.; Bektas, M. Psychometric properties of the Turkish version of the healthy lifestyle belief scale for adolescents. J. Pediatr. Nurs. 2020, 53, e57-e63. [CrossRef] [PubMed]

48. Emerich, M. The Gospel of Sustainability: Media, Market and LOHAS; University of Illinois Press: Champaign, IL, USA, 2011; pp. 21-26.

49. Pesek, T.J.; Helton, L.R.; Nair, M. Healing across cultures: Learning from traditions. EcoHealth 2006, 3, 114-118. [CrossRef]

50. Schrader, U.; Harrach, C. Empowering responsible consumers to be sustainable intrapreneurs. In Enabling Responsible Living; Schrader, U., Fricke, V., Doyle, D., Thoresen, V.W., Eds.; Springer: Berlin/Heidelberg, Germany, 2013; pp. 181-192. [CrossRef]

51. Ottman, J.A. The New Rules of Green Marketing: Strategies, Tools and Inspiration for Sustainable Branding; Berret-Koehler Publishers: San Francisco, CA, USA, 2011.

52. Osti, L.; Goffi, G. Lifestyle of health \& sustainability: The hospitality sector's response to a new market segment. J. Hosp. Tour. Manag. 2021, 46, 360-363. [CrossRef]

53. Natural Marketing Institute. Understanding the LOHAS Market; Report 2008. Available online: https://www.google.com/url? $\mathrm{sa}=\mathrm{t} \& \mathrm{rct}=\mathrm{j} \& \mathrm{q}=\& \mathrm{esrc}=\mathrm{s} \&$ source=web\&cd=\&ved=2ahUKEwiWheaRvtHxAhXs_7sIHZG2A0oQFjABegQIBhAD\&url=https $\%$ 3A \%2F\%2Fwww.lohas.se\%2Fwp-content\%2Fuploads\%2F2015\%2F07\%2FUnderstanding-the-LOHAS-Consumer-11_LOHAS_ Whole_Foods_Version.pdf\&usg=AOvVaw20Alx5WPIcMR6Rh06e4LFn (accessed on 17 March 2021).

54. Szakály, Z.; Popp, J.; Kontor, E.; Kovács, S.; Peto, K.; Jasák, H. Attitudes of the Lifestyle of Health and Sustainability segment in Hungary. Sustainability 2017, 9, 1763. [CrossRef]

55. Gaižauskaitè, I.; Mikènè, S. Socialinių Tyrimu Metodai: Apklausa; Mykolo Riomerio Universitetas: Vilnius, Lithuania, 2014.

56. Sielicka-Różyńska, M.; Jerzyk, E.; Gluza, N. Consumer perception of packaging: An eye-tracking study of gluten-free cookies. Int. J. Consum. Stud. 2021, 45, 14-27. [CrossRef]

57. LTstat. Inhabitants in Lithuania: Official Statistics. Available online: https:/ / osp.stat.gov.lt/statistiniu-rodikliu-analize?hash=2c3 61bfc-82ba-4c66-820e-94e7f3cfca29\#/ (accessed on 17 June 2021). 
58. Sarstedt, M.; Mooi, E. A Concise Guide to Market Research: The Process, Data, and Methods Using IBM SPSS Statistics, 3rd ed.; Springer: Berlin/Heidelberg, Germany, 2019.

59. Kohonen, T. Self-organized formation of topologically correct feature maps. Biol Cybern. 1982, 43, 59-69. [CrossRef]

60. Vesanto, J.; Alhoniemi, E. Clustering of the self-organizing map. IEEE Trans. Neural Netw. 2020, 11, 586-600. [CrossRef] [PubMed]

61. Calderon-Monge, E.; Pastor-Sanz, I.; Sendra Garcia, F.J. Analysis of sustainable consumer behavior as a business opportunity. J. Bus. Res. 2020, 120, 74-81. [CrossRef]

62. Clark, C.C.T.; Duncan, M.J.; Eyre, E.L.J.; Stratton, G.; García-Massó, X.; Estevan, I. Profiling movement behaviours in pre-school children: A self-organised map approach. J. Sports Sci. 2020, 38, 150-158. [CrossRef]

63. Kokkinos, K.; Karayannis, V.; Lakioti, E. Exploring social determinants of municipal solid waste management: Survey processing with fuzzy logic and self-organized maps. Environ. Sci. Pollut. Res. 2019, 26, 35288-35304. [CrossRef]

64. Furia, D.; Crociata, A.; Compagnucci, F.; Carlei, V. Similar patterns of cultural and creative industries. A preliminary analysis based on self-organized-map to the Italian case. In Decision Economics: In the Tradition of Herbert A. Simon's Heritage. DCAI 2017. Advances in Intelligent Systems and Computing; Bucciarelli, A., Chen, S.H., Corchado, J., Eds.; Springer: Cham, Switzerland, 2018; Volume 618, pp. 56-61. [CrossRef]

65. Tian, J.; Azarian, M.; Pecht, M. Anomaly detection using self-organizing maps-based k-nearest neighbor algorithm. PHM Soc. Eur. Conf. 2014, 2, 1-9. [CrossRef]

66. Brentan, B.; Meirelles, G.; Luvizotto, E.; Izquierdo, J. Hybrid SOM+k-means clustering to improve planning, operation and management in water distribution systems. Environ. Model. Softw. 2018, 106, 77-88. [CrossRef]

67. Kou, Y.; Cui, H.; Xu, L. The Application of SOM and k-means algorithms in public security performance analysis and forecasting. In Contemporary Research on E-Business Technology and Strategy. iCETS 2012. Communications in Computer and Information Science; Khachidze, V., Wang, T., Siddiqui, S., Liu, V., Cappuccio, S., Lim, A., Eds.; Springer: Berlin/Heidelberg, Germany, 2012; Volume 332, pp. 73-84. [CrossRef]

68. Adams, T.; Bezner, J.; Steinhardt, M. The conceptualization and measurement of perceived wellness: Integrating balance across and within dimensions. Am. J. Health Promot. 1997, 11, 208-218. [CrossRef] [PubMed]

69. Sabbagh, C.; Boyland, E.; Hankey, C.; Parrett, A. Analysing credibility of UK social media influencers' weight-management blogs: A pilot study. Int. J. Environ. Res. Public Health 2020, 17, 9022. [CrossRef]

70. Chen, K.K. Assessing the effects of customer innovativeness, environmental value and ecological lifestyles on residential solar power systems install intention. Energy Policy 2014, 67, 951-961. [CrossRef]

71. Lee, J.S.; Kwak, D.H.; Bagozzi, R.P. Cultural cognition and endorser scandal: Impact of consumer information processing model on moral judgement in the endorsement context. J. Bus. Res. 2021, 132, 906-917. [CrossRef]

72. Kwak, D.H.; Ma, X.; Kim, S. When does social desirability become a problem? Detection and reduction of social desirability bias in information systems research. Inf. Manag. 2021, 58, 103500. [CrossRef]

73. Savaneviciene, A.; Stancike, G.; Vaitkevicius, S. Individual innovativeness of different generations in the context of the forthcoming society 5.0 in Lithuania. Eng. Econ. 2019, 30, 211-222. [CrossRef] 